\title{
Myocardial systolic strain assessed by cardiovascular magnetic resonance relates to subclinical atherosclerosis in healthy young adults
}

\author{
Adam J Lewandowski, Merzaka Lazdam, Jonathan Diesch, Jane M Francis, Daniel Augustine, Rajarshi Banerjee, \\ Joseph J Suttie, Stefan Neubauer, Paul Leeson
}

From 2011 SCMR/Euro CMR Joint Scientific Sessions

Nice, France. 3-6 February 2011

\section{Background}

Cardiovascular magnetic resonance (CMR) allows quantification of early changes in systolic myocardial function. In the elderly, reduced left ventricular systolic function is related to elevated carotid intima media thickness (IMT), a well-established marker of atherosclerosis. We therefore sought to determine if peak myocardial systolic strain was also related to subclinical variation in carotid IMT and cardiovascular risk factors in young adults.

\section{Methods}

We recruited 68 individuals (39 females, 29 males) with a mean age of $28.29 \pm 5.45($ mean $\pm S D)$. Peak midventricular myocardial circumferential systolic strain and left ventricular mass adjusted for body surface area (LVM) were assessed by CMR. Carotid IMT was measured as a marker of subclinical atherosclerosis using ultrasound. Demographic and anthropometric characteristics were measured as well as metabolic parameters and peripheral blood pressure.

\section{Results}

Individuals with reduced peak myocardial circumferential systolic strain had higher carotid IMT $(r=0.406$, $P=0.001)$. Elevated total cholesterol and waist to hip ratio were both significantly associated with reduced myocardial strain. Increased LVM, peripheral systolic blood pressure, pulse pressure, glucose, triglycerides, age, BMI and WHR, as well as reduced HDL, were all significantly associated with increased carotid IMT $(P<0.01)$. Males also had higher carotid IMT than

University of Oxford, Oxford, UK
Cite this article as: Lewandowski et al:: Myocardial systolic strain assessed by cardiovascular magnetic resonance relates to subclinical atherosclerosis in healthy young adults. Journal of Cardiovascular Magnetic Resonance 2011 13(Suppl 1):095.

Submit your next manuscript to BioMed Central and take full advantage of:

- Convenient online submission

- Thorough peer review

- No space constraints or color figure charges

- Immediate publication on acceptance

- Inclusion in PubMed, CAS, Scopus and Google Scholar

- Research which is freely available for redistribution 